\title{
O ASSOCIATIVISMO NEGRO EM RIO CLARO: SUJEITOS, PRÁTICAS E IDEIAS NA REPÚBLICA
}

\author{
LAS ASOCIACIONES NEGRAS EN RIO CLARO: SUJETOS, PRÁCTICAS E IDEAS EN \\ LA REPÚBLICA
}
THE BLACK ASSOCIATIVISM IN RIO CLARO: SUBJECTS, PRACTICES AND IDEAS IN THE REPUBLIC

\author{
Pedro de Castro PICELLI ${ }^{1}$
}

RESUMO: Os clubes sociais de Rio Claro são fundados em fins do século XIX e tem como última data de organização o ano de $1951^{2}$. Portanto, o período histórico estrutural de formação destes clubes pode ser lido como um longo processo iniciado ainda no período escravista e que aponta na segunda metade do século XX para a existência, não necessariamente simultânea no tempo, de mais de uma dezena deles. A vivência associativa do espaço social apresenta-se como importante chave para pensarmos a transformação das relações sociais postas pós 1888. Assim, buscaremos neste breve artigo apresentar alguns dos clubes negros, membros e práticas para refletirmos as implicações das experiências destas associações para reposicionamento dos sujeitos e relações sociais no espaço social rioclarense.

PALAVRAS-CHAVE: Associativismo. Clubes sociais. Rio Claro. Pós-abolição. Racismo.

RESUMEN: Los clubes sociales de Río Claro son fundados a fines del siglo XIX y tienen como última fecha de organización el año de 1951. Por lo tanto, el período histórico estructural de formación de estos clubes puede ser leído como un largo proceso iniciado aún en el período esclavista y que apunta en la segunda mitad del siglo XX para la existencia, no necesariamente simultánea en el tiempo, de más de una decena de ellos. La vivencia asociativa del espacio social se presenta como importante clave para pensar la transformación de las relaciones sociales postadas después de 1888. Así, buscaremos en este breve artículo presentar algunos de los clubes negros, miembros y prácticas para reflejar las implicaciones de las experiencias de estas asociaciones para reposicionamiento de los sujetos y relaciones sociales en el espacio social rioclarense.

PALABRAS CLAVE: Asociaciones. Clubes sociales. Rio Claro. Abolicion. Racismo.

ABSTRACT: The associativism in Rio Claro was "founded" in the late nineteenth century and has the last date of organization in 1951. Thus, the structural historical period of club formation can be read as a long process begun even in the slavery period and which points in the second half of the twentieth century to the existence, not necessarily simultaneous in time, of more than

${ }^{1}$ Universidade Estadual de Campinas (UNICAMP), Campinas - SP - Brasil. Mestrando em Sociologia. ORCID: https://orcid.org/0000-0001-6598-8273. E-mail: pedrocastropicelli@gmail.com

${ }^{2}$ Em 1961 há uma transformação na denominação de um deles. Esta transformação é apontada posteriormente no texto e não considerada como um novo clube que se formara na cidade. 
a dozen of them. The associative experiences of social space present themselves as an important key to thinking about the transformation of social relations after 1888. Thus, we will seek in this brief article to present some of the black clubs, members and practices to reflect the implications of the experiences of these associations for th repositioning of subjects and social relations in the social space of Rio Claro.

KEYWORDS: Associativism. Social clubs. Rio Claro. Post abolition. Racism.

\section{Da Frente Negra, Gama e Patrocínio: os clubes sociais negros de Rio Claro}

O primeiro clube social negro registrado em periódicos da cidade de Rio Claro data do ano de 1930. Embora esta data seja passível de questionamento e abra espaço para a especulação da existência de outras organizações sociais negras anteriores a ela, a usamos como um marco temporal para nos questionarmos, assim como Pereira (2008, p. 37), "o que significaria para o negro, então, morar numa cidade esmagadoramente branca e a que tipo de constrangimento racial estaria submetido?" Recorrentemente, os jornais rio clarenses, como indica essa autora, traziam em suas seções de classificados anúncios como os que reproduziremos abaixo:

\section{Figura 01}

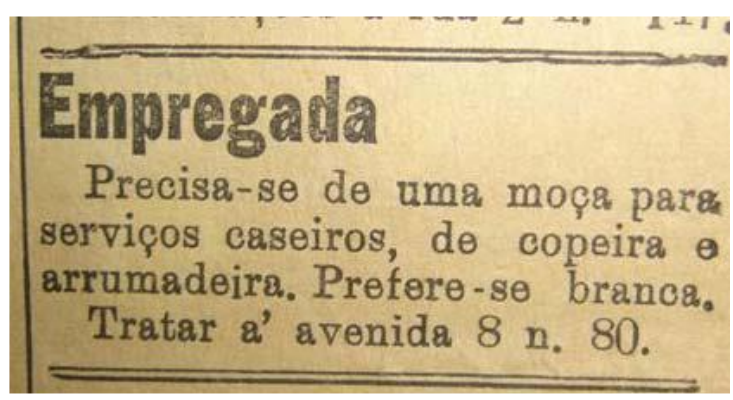

Figura 02

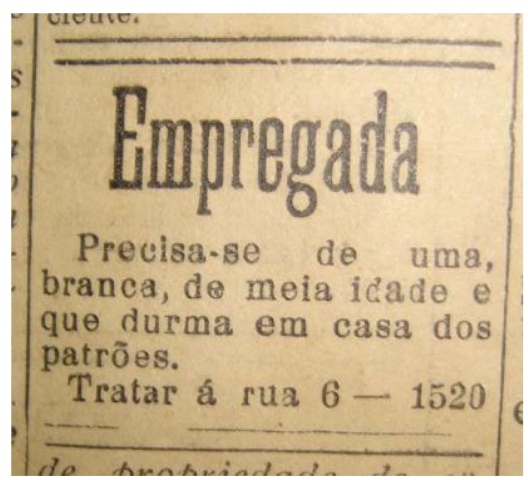


Somadas à seção de classificados, charges costumavam ser apresentadas no corpo dos jornais. Uma delas retoma a temática da racialização dos membros da sociedade rio clarense:

\section{Figura 03}

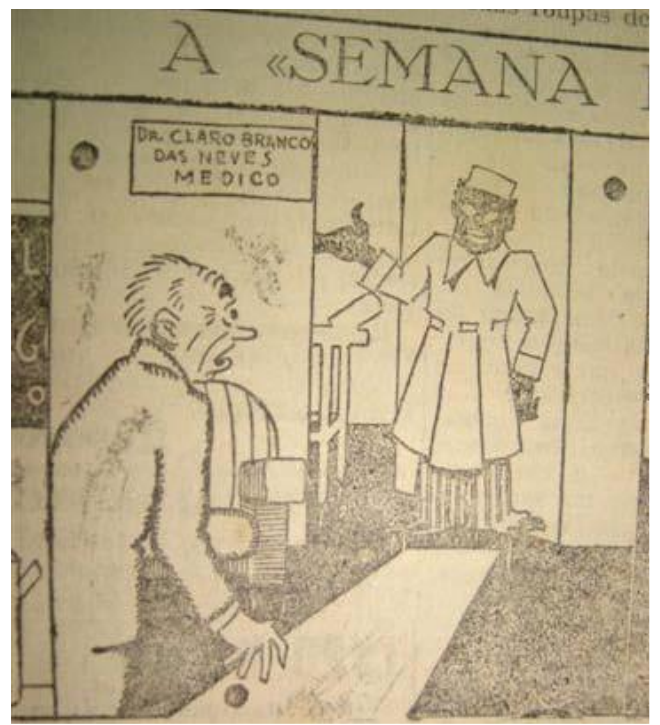

Além desta questão a imagem

[...] projeta a ideia da contrastividade, dos papéis fora do lugar e da perplexidade inconformada branca diante da aberração e da brutalidade negras - note-se que a porta do consultório parece ter sido literalmente arrombada pelo médico caricaturado preto, "doutor Claro Branco das Neves" (PEREIRA, 2008, p. 38)

As imagens circuladas pelos veículos de comunicação privados da cidade de Rio Claro nos permitem identificar as posições e expectativas sociais criadas sob grupos a partir da racialização de seus membros. A empregada doméstica - eufemisticamente chamada de "moça para serviços caseiros - deve ser preferencialmente branca, colocando centralidade à forma de classificação racializante, mesmo que o fim a que se busca obter seja o idêntico: a exploração da força de trabalho. Outro "desajuste" social que as ideias contidas na terceira gravura nos trazem é, em primeiro lugar, a implausibilidade de aceitar-se um médico negro na cidade nas primeiras décadas do século $\mathrm{XX}$ e, secundariamente, como grupos brancos e negros são direcionados às expectativas sociais produzidas nas próprias relações postas no espaço físico da cidade. É importante ressaltar que estas práticas racistas estão inseridas em espectros mais amplos e postos em um contexto nacional e, de certa forma, global no período.

O Diário de Rio Claro de 25 de junho de 1933 traz em suas páginas principais uma matéria intitulada "Dentro de pouco, não haverá mais pretos no mundo - Foi descoberta uma 
planta que torna branca sua epiderme". No ano seguinte, em 13 de julho de 1934, o mesmo periódico veicula um artigo denominado "Prevenção racial". Desse modo, a busca pelo embranquecimento social torna-se uma pretensa nas relações postas no país. Assim, como afirma Schwarcz (2012, p. 44), "quanto mais branco melhor, quanto mais claro mais superior, eis aí uma máxima difundida que vê no branco não só uma cor, mas também uma qualidade social".

Contudo, essa política de branqueamento social é uma das complexidades de um processo de ordenamento social mais amplo e intencional. Outra dimensão dele é a articulação da categoria raça a partir da ideia de predisposição de determinados grupos a desenvolverem potencialidades e características próprias, ocupando, portanto, determinados lugares sociais dentro de suas capacidades inatas. Cabe aqui apresentar um texto do alemão Dr. Ernesto Müller, reproduzido no jornal Cidade de Rio Claro em 1935, e apontado por Pereira em seu trabalho:

Quando alguns paizes tiraram as primeiras conseqüências legislativas dos resultados da doutrina moderna das raças, este procedimento foi, por parte de alguns povos, mal-entendido e mal interpretado. Levantaram-se, aqui e acolá, vozes que chamaram de contrário à civilização qualquer introducção de idéias racistas na vida política, ou declarando-a atè politicamente perigosa. Taes juizos, já por si só, deviam provocar surpreza, porque grande parte dos povos civilisados sempre tem tido principios evidentes racistas, bastando a lembrar a posição e procedimento da Inglaterra e dos Estados Unidos da America do Norte. A adversão contra a idéa racista só se explica pela habil e systematica diffamação que especialmente interessados promoveram contra as concepções racistas, e, visando sobretudo as da Nova Alemanha.

O pensamento racista não se identifica de forma alguma com o menosprezo de outras raças, nem pretende consideral-os de inferiores, mas accentua, para todas as raças e povos do mundo, a necessidade de guardar e desenvolver as propriedades caracteristicas que o Creador lhes deu.

Assim, não se fala na Allemanha da "inferioridade" de quesquer grupos humanos, mas tão sómente da sua "variedade", rejeitando o cruzamento quando considerado prejudicial para ambas as partes. Com esta concepção, a Allemanha encontra-se no mesmo ponto de vista em que se acham, há muitos seculos, entre outros, os povos do Oriente, cujo conceito pronunciado de familia e culto dos antepassados lhes impõem o dever de zelar pela pureza das suas familias. Assim, o conceito racista não conduz, absolutamente, a hostilidade e lutas mútuas, mas antes a consideração recíproca que é a unica base para crear relações pacíficas entre homens e povos (PEREIRA, 2008, p. 75).

Dentro deste contexto social, reservam-se aos negros e negras o além das margens- que não são lugares de imobilidade - de todo o convívio social. Os dados de pesquisa e a consulta aos arquivos nos revelaram que estes sujeitos eram, em sua ampla maioria, autônomos voltados para ocupações braçais. As fichas de registro de sócios da José do Patrocínio organizadas no ano de 1980 - mas que continham dados desde a década de 1960 - nos fornecem importantes 
informações a este respeito. Entre mais de 85 fichas, as profissões mais recorrentes foram: operários de máquinas, domésticas, militar, pedreiros, seguranças, guardas noturno, pintores, motoristas particulares, cozinheiras, marceneiros. Ainda consta a presença de um advogado e de um bancário. Dentre as entrevistas realizadas com os membros dos clubes negros, percebemos a recorrência destes mesmos empregos. Seu Paulo Martins é mecânico geral e formou-se enquanto técnico de segurança do trabalho. Seu Djalma de Paula trabalhara como mecânico de manutenção em uma das indústrias da cidade. Dona Estela foi empregada doméstica e seu Celso Augusto, trabalhara no exército, seguidamente nas oficinas da Paulista. Rememorando os tempos familiares, Dona Estela ainda retoma a profissão de alguns parentes.

Meu pai era motorista da Paulista. Antes trabalhava no Horto Florestal e depois foi pra Paulista. Aí fazia ou o caminho ou a ambulância, que levava os pacientes da companhia pra algum lugar. Minha mãe era da época do Matarazzo $^{3}$ ainda. Eu, infelizmente, não peguei essa época boa de firma e fui empregada doméstica, que até hoje dou graças a deus pelas casas que eu passei $^{4}$.

A maioria dos sócios morava em Rio Claro, contudo, cidades como Limeira, Piracicaba, São Carlos, Santa Gertrudes, Bariri e São Paulo são encontradas neste cadastro. Os moradores de Rio Claro residiam em bairros periféricos, como os bairros Vila Nova e Arco Íris. Além dos empregos autônomos, uma parte da população negra masculina de Rio Claro trabalhava na Companhia Paulista de Estradas de Ferro. Como afirma Pereira:

[...] sobretudo para os negros do interior paulista, onde o binômio racismodiscriminação obstaculizava ainda mais a ascensão desse grupo, não era pouca coisa conseguir emprego na "Paulista". Trabalhar nessa empresa significava estabilidade no emprego, possibilidade de ascensão em termos de cargo, regularidade no recebimento do salário, facilidade para aquisição de terreno residencial, acesso a medicamentos via convênio, acesso a bilhete de passagem gratuita para viagens de trem (os dois últimos extensivos à família), e assim por diante (PEREIRA, 2008, p. 115).

O que se nota, portanto, é a distribuição da população negra em posições sociais de baixo prestígio social. Entretanto, a distribuição destes sujeitos pela teia social não era caracterizada por sua imobilidade, e sim pelo conflito. Uma prova da disputa do espaço social e geográfico de Rio Claro foram os festejos e práticas associativas deste grupo. O Tambu ou Samba do 13 foram construídos na cidade desde o início do século XX. Marcado pelo ritmo do Tambu - instrumento de percussão feito com madeira e couro - e realizada "no largo do São

3 Fábrica de tecelagem instalada em Rio Claro na década de 1950.

${ }^{4}$ Entrevista concedida a Pedro de Castro Picelli em dezembro de 2016. 
Benedito, autêntico quilombo urbano de Rio Claro na época (hoje bairro central)" (Pereira, 2008, p. 80), era para “celebrar" o 13 de maio.

[...] os negros elaboravam um espaço autônomo próprio, com liberdade para estabelecer seu próprio ritmo, sua própria linguagem poético-metafórica improvisada e sua própria corporalidade. Esse era o espaço da interação, da motivação, da satisfação e da identidade coletivas. Ali os próprios negros selecionavam o que devia ser incluído ou excluído, o que devia ser lembrado ou esquecido. É nesse espaço, capaz de reunir passado e presente, natureza e cultura, que os negros subvertiam a sociedade abrangente, celebrando sua cultura de matriz africana (SABINO, 2005).

Além do Samba do 13, o Tambu era realizado também em comemoração ao dia de São Benedito aos pés da figueira histórica localizada em frente à igreja deste santo. Em 13 de maio de 1913, o jornal O Rio Claro anunciou: "Realiza-se no dia 13 do corrente a festa em louvor a S. Benedicto. Haverá missa cantada e a tarde imponente procissão percorrerá o itinerário de costume". Contudo, após duas décadas de festejos, O Diário de Rio Claro, de $1^{\circ}$ de agosto de 1933, dá mostras de que tal prática começara a se tornar indesejada por alguns grupos da cidade. Este indício refere-se à possibilidade de derrubada da figueira ancestral, como explicita o artigo publicado no periódico citado:

A nossa figueira

Há quem opine pela destruição da nossa legendária figueira, a ponto de nos assediarem para que empreguemos nossos esforços para esse fim, o que temos recusado. Auscultando, que temos, a opinião dos habitantes deste bairro, concluímos que a maioria é contrária a destruição da bella árvore quase secular.

Agora si a figueira falasse... e puzesse a público e raso as suas culpas, ella seria digna de um bom machado.

A prática do Tambu ocorreu ainda no largo em maio de 1937. Porém, o Diário veiculava no dia 29 de junho deste mesmo ano a seguinte notícia:

Os nossos homens de côr, na véspera e dia de S. João, fizeram realisar no pateo de S. Benedicto, dois retumbantes sambas, como despedida do local onde há tantos annos os adeptos do "batuque" festejam o dia da libertação dos escravos no Brasil.

É que aquelle largo vae receber o seu ajardinamento que o tornará mais attractivo, fazendo jús a belleza da egreja do milagroso Santo preto, cousa aliás que há muito se fazia sentir.

Veremos agora, no proximo 1938, qual irá ser o local designado pela prefeitura para ser commemorada a data de 13 de maio, por nossa gente de cor. 
Em 1938, o Samba continuou a ser realizado no Quilombo do Largo de São Benedito. Contudo, em 1939, “os praticantes do Tambu tiveram de dizer adeus ao largo de São Benedito, pois, a administração Penteado os havia empurrado para uma região mais afastada da cidade, a saber, o largo de São Roque (sito à avenida 5, entre ruas 12 e 13)" (PEREIRA, 2008). Nos festejos de 1939, incluíram-se, como nos mostra o Diário de Rio Claro de 11 de maio de 1939, além do Samba do 13, uma missa exclusiva para negros e negras ainda na Igreja de São Benedito e uma romaria que caminharia até o cemitério municipal. Pereira (2008), analisando esta mudança de local dos festejos, afirma que

[...] a nota faz ver que os praticantes do Tambu - genericamente chamado de "batuque" pelos brancos - estavam sendo expulsos do espaço no qual realizavam, historicamente, sua manifestação de matriz africana. Sob o pretexto de "ajardinamento" procurava-se, na realidade, eliminar o que se tomava por "manifestação primitiva dos pobres descendentes de escravos de Rio Claro", pondo fim ao "resquício escravista" já tão ultrapassado e incongruente com a ideia de ordem, de progresso e de modernidade para a época. Tal processo configura um projeto de varrição étnico-racial no meio urbano, pois tratava-se de desenegrecer o Quilombo (nome original do bairro), lugar que os pretos haviam cunhado como um espaço físico e simbólico próprio no plano local (PEREIRA, 2008, p. 101-102).

É neste contexto social de expulsão e "patrulhamento" dos festejos de ocupação do espaço público pela população negra que surgem as primeiras coletividades associativas negras. A possível primeira sociedade negra na cidade fora a Sociedade Dançante 28 de Setembro, fundada em 1930. O nome fora dado em referência à promulgação da Lei do Ventre Livre, nesta mesma data só que 59 anos antes. Presidida por Hygino Arruda, pouca coisa foi encontrada sobre sua existência na cidade de Rio Claro. Entretanto, pode-se saber sobre ela a partir da divulgação, no Diário do Rio Claro, de 23 de fevereiro de 32, de outra associação negra que se estabelecia na cidade em 1932: a Frente Negra Brasileira (FNB).

\section{Figura 04}

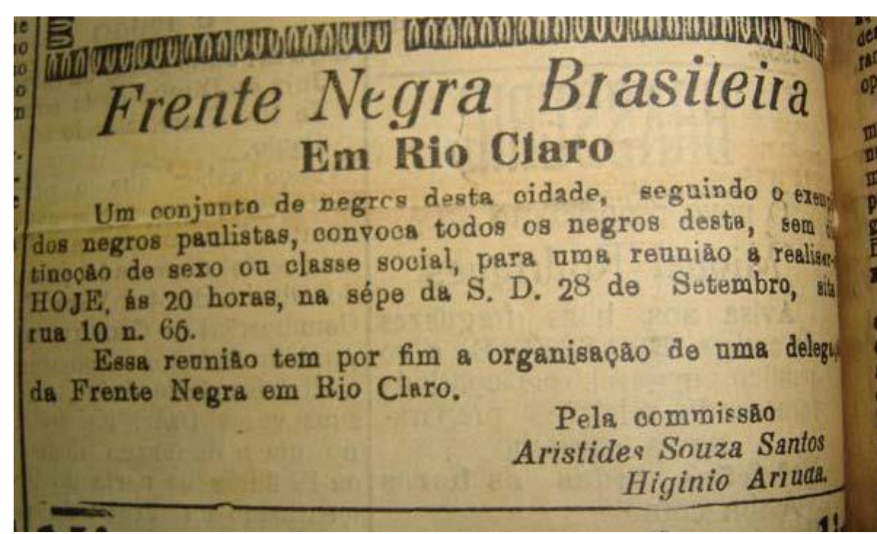


Petrônio Domingues retoma a fundação da Frente em Rio Claro a partir da reunião presidida por Aristides dos Santos. No início dos trabalhos desta reunião,

[...] ele falou da necessidade de se congregarem, todos os seus irmãos de raça, em torno da Frente Negra, que surge como a bandeira redentora que garantirá e pleiteará os direitos dos negros dentro do Brasil". Três dias depois, outro jornal da cidade, O Batutinha ("Órgão crítico, literário e social - Dedicado aos homens de cor"), estampava na primeira página: "Negros de Rio Claro! Está organizada a Frente Negra Brasileira em Nossa cidade. Ergue-te e vem colaborar em prol de nossa verdadeira liberdade (DOMINGUES, 2010, 116).

Na mesma edição de $O$ Batutinha fora noticiada também a composição da diretoria eleita para dirigir a delegação da Frente Negra em Rio Claro. Hygino Lucio de Arruda seria o presidente, João de Souza, o vice; o primeiro e segundo secretários seriam, respectivamente, José Ignácio do Rosário e Aristides Negreiros; tesoureiro, Benedicto Teixeira; conselheiros, Aristides Souza Santos, Waldomiro Gonçalves, Alberto Christiano, André José Gaudio, Sebastião de Almeida, Juvenal dos Santos, Lázaro Carneiro e Manoel Domingues; delegado especial de FNB em Rio Claro, José Ignácio Ramos. Em seu início, a Frente tivera sede na Rua 4, número 94, hoje centro da cidade - e à época, afastado dele - e permanecia aberta todos os dias

[...] atendendo aos interessados das $11 \mathrm{~h} 00$ às $20 \mathrm{~h} 00$. Um número cada vez maior de negros foi compreendendo seus "nobres" ideais de igualdade racial e, movidos por um clima de entusiasmo, expectativa e esperança, acorreram à sede para assomar-se aos seus quadros de associados. Com a estruturação, ela adquiriu um novo dinamismo, empreendendo programas culturais e projetos sociais. Talvez o principal deles foi a criação de uma unidade de ensino. Já no final de abril de 1932, a diretoria da agremiação relatava que estava prestes a abrir uma "escola instrutiva noturna", dirigida pela professora Maria de Lourdes Rosário, "que com verdadeiro amor, esforço e franca dedicação" contribuiria para o feliz andamento do estabelecimento (DOMINGUES, 2010, p. 116-117).

Essa escola noturna iniciara suas atividades no início de maio de 1932, inserida em um projeto político mais amplo. Em linhas gerais, como aponta Pereira (2008), este projeto da Frente Negra versava "instruir em moral e em intelecto o negro brasileiro, principalmente após os anos 1930". Este "novo" negro construir-se-ia como porta voz de um protesto racial moderno. Desta maneira, a FNB não fora exclusividade enquanto associativismo negro em Rio Claro no período.

No ano da fundação da escola "nocturna frentenegrina, voltada para instrução e alphabetisação dos "irmãos da raça" (PEREIRA, 2008, p. 57), é observado o surgimento de dois outros clubes associativos negros: a Sociedade Beneficente e Instrutiva Henrique Dias e a 
Associação José do Patrocínio. A primeira fora fruto da primeira cisão ocorrida na delegação rio clarense da FNB, e que se organiza em torno de Jurandir Mourão. Em 19 de abril de 1932, este grupo organizado por Mourão publica no Diário do Rio Claro uma breve nota que convoca "todos os elementos da raça" para uma "sessão solene" que se realizaria na Sociedade 28 de setembro, às 20 horas. Como observa Domingues:

\begin{abstract}
A "sessão solene" consistiu na reunião de fundação da Sociedade Beneficente e Instrutiva Henrique Dias. Bastante concorrida, a reunião foi aberta com um longo discurso de Waldomiro Gonçalves, que explicou aos presentes os fins beneficentes da nova sociedade. Historiando a cisão da Frente Negra, o "orador concluiu por dizer que os negros brasileiros não podem se escravizar a partidos políticos, uma vez que se querem homens livres e independentes". Com o nome em homenagem ao "heroico patrício, homem de cor que se bateu pela nossa pátria", expulsando os holandeses do Nordeste brasileiro no período colonial, a Henrique Dias definiu sua diretoria, com a seguinte nominata: Presidente, Hygino Lúcio de Arruda; Vice-Presidente, João de Souza; Primeiro Tesoureiro, Juvenal dos Santos; Segundo Tesoureiro, Lázaro Carneiro; Primeiro Procurador, André Gaudio; Segundo Procurador, Mário de Souza; Primeiro Secretário, Jurandir Mourão; Segundo Secretário, Áureo Baptista; Conselheiro, Waldomiro Gonçalves (DOMINGUES, 2010, p. 123124).
\end{abstract}

É curioso notar que boa parte dos membros diretores da Frente de Rio Claro foi compor os quadros diretivos da nova associação. Esta sociedade caracterizara-se, diferentemente da FNque se definia enquanto "uma união política e social da gente negra para o levantamento geral da raça, intellectual e moral, e não (...) [para] dansas e outros divertimentos" - 5 pela realização de festejos. Estes reuniam a população negra da cidade em torno de bailes embalados, principalmente, pelo som do jazz da Jazz Band Batutas Rio Clarenses. Dentro desta sociedade também se formou um Grupo Dramático, responsável pela organização dos eventos culturais. Ao longo da pesquisa, não se achou nenhum tipo de referência a uma sede específica deste clube, portanto, supõe-se que a maioria dos eventos eram realizados nas dependências do 28 de setembro.

A Associação José do Patrocínio também fora fundada em 1932 e, como aponta Domingues (2010, p. 194), igualmente "pelejava em prol da elevação moral, social e cultural do elemento de cor”. Presidida inicialmente por Júlio de Lima, esta sociedade é composta inicialmente de membros oriundos das outras associações apresentadas anteriormente e situarase, ao longo de toda sua existência, na mesma sede que a delegação da Frente Negra em Rio Claro. Desta maneira, muitas vezes ambas eram confundidas ou pensadas como uma sociedade unitária, o que causara inúmeros incômodos na Frente. Um destes incômodos foi expressado

${ }^{5}$ Diário do Rio Claro, de 22/05/1932 
no jornal Diário de Rio Claro de 22 de maio de 1932, quando o secretário geral frente negrino afirmou que mesmo sediadas em um mesmo lugar, elas não tinham nada que ver uma com a outra já que é "sobejamente conhecido que esta é uma união política e social de gente negra para o levantamento geral da raça, intelectual e moral, e não de danças e outros divertimentos". Cabe apontar que em 1934 a Frente Negra em Rio Claro desaparece quase que completamente, ao passo que a José do Patrocínio ainda continua suas atividades. Estas atividades tinham como pontos altos os bailes dançantes realizados ao longo de todo ano e os festejos de carnaval que se reuniam em torno da organização do cordão carnavalesco da sociedade. Sob estes moldes de bailes e festejos, é fundada em 1934 a Sociedade Dançante Familiar Progresso da Mocidade, presidida por Francisco Franco Arruda - eleito vice-presidente da segunda gestão da Sociedade 28 de Setembro e que especulamos possuir algum parentesco com Hygino de Arruda. O Diário do Rio Claro, de 7 de março de 1935, traz uma notícia sobre a participação destas sociedades no carnaval rio clarense.

Seriamos injustos si não destacassemos, como merecem, os cordões da nossa gente de côr. Estão de parabens os esforçados dirigentes da sociedade "28 de setembro" e "Progresso da Mocidade" pela sua optima contribuição ao nosso Carnaval. As sociedades da nossa folionica gente de cor nos deu dois cordões em perfeita linha, correctos e de uma organisação perfeita. Além do mais, cantavam e dansavam no compasso, percebendo-se perfeitamente o canto, como si fosse entoado a uma só voz. A nossa gente de côr "fez bonito", mesmo, os seus cordões agradaram bastante e geralmente...

No ano de 1935, é noticiado nos jornais de maior circulação na cidade de Rio Claro Diário do Rio Claro e Cidade de Rio Claro - as atividades de mais uma sociedade que se funda na cidade, a Sociedade Uma Noite de Alegria. Entretanto, as informações só dão conta da participação desta associação nos festejos carnavalescos, e não podemos precisar maiores informações sobre ela. Entretanto, podemos registrar com detalhes a formação de outra sociedade dois anos depois. Em 9 de outubro de 1937, é fundado o Centro Cívico e Beneficente Luís Gama.

Como recupera Domingues (2010) no jornal A Voz da Raça, tratava-se de uma "iniciativa dos homens de cor altivos e operosos", formadores da "elite negra rioclarense". Prossegue o autor:

O jornal Cidade de Rio Claro ${ }^{6}$ também informou aos leitores das solenidades de inauguração do Centro Cívico e Beneficente Luiz Gama, a novel associação que reuniria a "maioria dos homens de cor" do município. Segundo a reportagem, o Luiz Gama teve, desde o princípio de sua formação, uma

${ }^{6}$ O periódico citado é o Cidade de Rio Claro, de 09/10/1937 
trajetória "invulgar e brilhante", conseguindo acardumar, sob sua bandeira, cerca de 320 sócios. As finalidades estatutárias da associação seriam "das mais louváveis e meritórias", quais sejam, propugnar uma assistência cotidiana e diligente, tendo em vista proporcionar "ao homem de cor da cidade todo o conforto de que necessite na sociedade"; tornar-se um reduto de "comunhão da raça"; procurar alfabetizar aqueles que ainda não o são; criar um ambiente "cooperativista de mutualidades" capaz de assegurar aos associados uma "união beneficiadora"; ser, portanto, "amparador" e cívico, como o seu próprio nome indicava (DOMINGUES, 2010, p. 126).

Esse Centro foi presidido por Hygino de Arruda, antigo presidente da Sociedade 28 de Setembro, e vice presidido por Francisco Arruda, ex-presidente da Progresso da Mocidade. As atividades desta sociedade eram semelhantes às dos clubes anteriores, além de mobilizar discussões políticas entre a população negra da cidade. É interessante observar que até este clube a ausência de uma sede fixa representava recorrentemente um problema para estas sociedades. Pereira (2008, p. 176) reflete sobre isso e afirma que um dos objetivos destas organizações era "solucionar o problema da provisoriedade das sedes negras, rompendo com o ciclo dos espaços intermitentes da raça". Este impasse, como prossegue a autora, "acompanhou as organizações negras locais desde (pelo menos) os anos 1930, historicamente impossibilitadas de levar adiante seu projeto coletivo de construção da casa própria”. Muitas das reuniões e encontros se realizavam na casa de membros das associações ou na sede da Sociedade 28 de Setembro e que acabou se tornando das outras associações. Flávia de Souza Pereira sugere que a impossibilidade de se construírem sedes fixas e próprias ocorre devido ao "crescimento econômico e político dos imigrantes/descendentes que sufocou a formação de uma classe média negra econômica e politicamente expressiva em Rio Claro.”

A década de 1940 marca uma lacuna na formação de novas sociedades e dos festejos dos clubes sociais negros existentes e nas atividades carnavalescas da cidade. A prefeitura, ao longo de toda a década de 40, praticamente não investiu nas atividades do carnaval local. Como ressalta Pereira (2008), os festejos carnavalescos constituíram-se como um "importante termômetro para o diagnóstico da saúde das organizações negras". Desta maneira, com o investimento nulo por parte do poder público, os grupos negros passaram a se defrontar com dificuldades estruturais de manter a própria atividade das sociedades já existentes. O fim da folia do Momo em Rio Claro foi destaque no Diário do Rio Claro de 4 de fevereiro de 1945

O Carnaval de rua parece ir morrendo aos poucos, pelo menos enquanto a guerra não terminar, porque podemos adiantar aos nossos prezados leitores que Rio Claro terá ainda um Carnaval com Rei Momo em "carne e osso", carros alegóricos etc. 
De certa forma, nosso argumento caminha muito próximo ao da autora quando sugere que é totalmente coerente afirmar que, em termos estruturais, as organizações negras rio clarenses chegam a 1945 quase sem fôlego algum. Isso se deve, em um panorama mais amplo, por dois motivos centrais. O primeiro já foi exposto e se resume à falta de suporte do poder local do período - Sólon de Mendonça Rego Barros, do Partido Republicano Histórico, fora nomeado prefeito de Rio Claro em 1940 pelo interventor Adhemar Pereira de Barros, do antigo Partido Republicano Paulista -. A segunda razão consiste no clima de tensão oriundo dos efeitos da Segunda Guerra Mundial.

Contudo, em 25 de setembro de 1948, é fundada a Sociedade Dançante Familiar José do Patrocínio. Presidida por José de Andrade, a sociedade tinha como finalidade estatutária o oferecimento às famílias associadas entretenimento dançante e recreativo. Desta maneira, bailes, domingueiras dançantes e um cordão carnavalesco eram desenvolvidos pelos seus membros. Em 1960, essa sociedade é reorganizada como Sociedade Beneficente Recreativa José do Patrocínio, como consta em estatuto datado de 1967. Em sua maioria, os membros deste clube eram oriundos das atividades relacionadas à Companhia Paulista. Maquinistas, trabalhadores do trilho, trabalhadores das oficinas reuniram-se em torno desta sociedade. Seu Celso Augusto $^{7}$ nos indicou que esta mudança de nome fora decorrência do processo de conquista do terreno para a construção de uma sede própria, e de diversas reuniões com o poder público. Em uma delas, nos conta Celso Augusto:

Celso Augusto: Tinha bastante gente das oficinas, era secretário da prefeitura, gente lá do horto, era chefe de turma da raça nas oficinas, aí achou que não podia fazer uma sociedade só, porque tinha o tal de Barbosa, Aristides que estavam estudando pra professor e não podiam formar uma sociedade só pra esses neguinhos pé-de-chinelo virem dançar com a filha deles. Foi um rolo. Uma discussão do caramba. Aí o prefeito estava presente nessa reunião e bateu na mesa bravo dizendo que ia dar um terreno grande pra fazer o que a gente quisesse, ali na Avenida da Saudade, perto do cemitério municipal. Ele ia doar ali pra nós

Pedro: Um terreno para a Sociedade Dançante Familiar José do Patrocínio?

S.C: Não. Essa era a que nós usamos pra "renascer" o Patrocínio!

Pedro: Em 60, ela mudou de nome para poder receber o terreno?

Celso: Sim. E foi com nós. Ficou Beneficente pra poder receber verba e não pagar imposto, ou seja, conseguir ajuda da prefeitura.

Desta maneira, é apenas em 1960 que um clube negro na cidade de Rio Claro conquista um terreno para a construção da sede. A partir das entrevistas realizadas com os membros da Sociedade Beneficente Recreativa José do Patrocínio conseguimos recuperar informações

${ }^{7}$ Entrevista concedida a Pedro de Castro Picelli em dezembro de 2017 
importantes a respeito da construção desta sede. Dona Estela, uma das pioneiras do clube, rememorou este período e achamos muito válido reproduzir o depoimento na íntegra:

Pedro: Agora entrando um pouco mais no assunto do lançamento da pedra fundamental, da construção do Patrô. A senhora tem alguma recordação? Lembra do quão importante isso foi pro clube? Onde era a sede antiga, onde aconteciam as reuniões?

Dona Estela: Não tinha sede antes. Não tinha. Ou as reuniões eram feitas na casa de membros do clube. Mas não tinha uma sede, um lugar que pudesse discutir isso, fazer isso, fazer aquilo, era tudo decidido nesses lugares, até correr atrás da prefeitura e conseguir um espaço. A construção se deu na base do pedi daqui, pedi de lá (risos). Era cerâmica, era onde fazia telha, qualquer lugar que tivesse algo pra contribuir com a gente, nós estávamos lá...

P: E tinha alguma resistência na cidade em se construir essa sede?

D.E: Que eu saiba não. Nunca soube de nada disso. A única coisa que a gente tinha na época, não sei se a revolta era grande, porque, agora que a gente tinha nossa sede, por que que branco vai frequentar? Então também havia essa polêmica na nossa sociedade (risos). Até que graças a deus, com o passar do tempo, nós conseguimos receber os brancos lá dentro antes de nós podermos frequentar os (clubes) deles...

P: Antes era possível brancos frequentarem os eventos das sociedades?

D.E: Era impossível. Vinha, inclusive, gente de fora tentar entrar na nossa escola de samba, mas não era permitido.

P: E aí, na construção, quando eu pergunto se existiu alguma resistência, eu digo de pessoas não quererem que aquilo acontecesse, como a doação do terreno.

D.E: Não, não. Que eu saiba não. Todo pessoal que colaborou com a gente... Não lembro (das pessoas que ajudaram). A única coisa que eu lembro era o Bazar Paulista que nos ajudou muito, que hoje nem tem mais. Tinha uma Casa das Novidades que nos ajudou...

P: E a senhora lembra o tempo que demorou para inaugurar a sede?

D.E: E agora? A construção o Carlos (filho de Dona Estela) era pequenininho, não demorou muito não porque minha filha é de 63, em 66 a arrecadação de dinheiro já tinha sido feita... Acho que foi bem antes. Não demorou muito tempo, porque nós tínhamos a Princesinha Negra, que era uma festa como forma de arrecadar dinheiro e a minha filha participou. Coloquei ela com dois anos e meio, acho que na época, quase 3, por falta de... sabe, pra ter criança mais ali no meio. Então, eu acho que deve ter sido mais ou menos em $63 .$. A pedra fundamental foi lançada em 62, eu acho que em 63 pra 64 já estava pronta.

Em síntese, a sede do Patrocínio representou uma conquista do grupo negro da cidade embora localizada em uma área afastada do centro. Conquistara-se o material para a construção a partir do esforço dos próprios membros do grupo em articular sujeitos dentro e fora da sociedade para que pudessem angariá-lo e iniciar a construção do prédio. É importante apontar que toda a mão de obra utilizada para o erguimento da "casa própria" fora de sócios do próprio clube que viraram dias e noites para concretizarem esse desejo. Seu Celso Augusto também rememora este período: 
Pedro: Os senhores que ergueram ali a sede do Patrocínio? O senhor lembra como foi o período da construção?

Celso Augusto: Foi lançada a pedra fundamental e começamos a fazer o tal de livro de ouro e ia às olarias que davam e falavam como faziam, assinavam o livro de ouro e davam as coisas. Em Batovi, eles doavam pra nós tijolo e pedra pra fazer o serviço...

P: E a mão-de-obra foi tudo com os senhores?

C: Tudo! Demorou mais ou menos uns quatro anos. Primeiro, nós não tínhamos lugar pra dançar, aí o Schimitd (Augusto Schimitd, então prefeito de Rio Claro) tinha formado o ginásio de esportes e cedeu pra nós fazermos o carnaval ali, bailes... Tudo pra arrecadar dinheiro pra fazer a sede.

P: Vocês tinham que pagar algo à prefeitura?

C: Não, não. Uma vez era o Tamoio que fazia, outra vez era o José do Patrocínio que fazia eventos ali pra arrecadar dinheiro. Era durante o ano inteiro: formatura, essas coisas era tudo ali. A negrada fazia tudo ali onde é o ginásio de esportes. Ele deu uma boa mão pra gente. Graças a deus não tenho queixa.

Após a conquista da sede, os bailes passaram a ser mais frequentes e temáticos. Recebendo apenas sujeitos negros e trajados de gala, as noites dançantes eram animadas especialmente ao som de jazz de bandas - majoritariamente compostas por músicos negros provenientes da cidade de Rio Claro e da região. Como relembra Seu Edmur Augusto ${ }^{8}$, o conjunto de atividades do clube era formado pelo Baile do Champagne, Baile da Jóia Negra, Baile das Debutantes, Reveillon, Baile Vermelho e Branco, além das domingueiras dançantes e das matinês do carnaval. A preparação dos cordões - e na década de 1960 - da escola de samba era outro ponto alto das atividades da José do Patrocínio. Como rememorado por todos os entrevistados, estes bailes eram frequentados exclusivamente por negros, mas não apenas os de Rio Claro, sujeitos vindos de Limeira, Piracicaba, Jundiaí, São Carlos, Araraquara, Batatais lotavam as dependências da sociedade.

Em 1951, antes mesmo da construção da sede pelo José do Patrocínio, é fundado o Tamoio Futebol Clube, nome dado em referência ao orixá Oxóssi. Sediado na Avenida 23, entre as Ruas 13 e 14, localiza-se muito próximo à S.B.R. José do Patrocínio até os dias de hoje. A conquista do terreno para a construção do prédio que abrigaria a sociedade se dá no mesmo processo que ocorre no caso do Patrocínio e que se apresentara anteriormente. A partir de uma luta travada com o poder público e com a angariação de materiais e fundos para as obras, a “casa própria" foi erguida pelos próprios membros da sociedade. Estes eram sujeitos que garantiam seu sustento em trabalhos braçais, como marceneiros, pedreiros, domésticas, lavadeiras, guardas noturnos, etc. e que não estavam majoritariamente dentro de cargos da Companhia Paulista. Inicialmente, as atividades do clube eram dedicadas à prática do futebol.

8 Entrevista concedida a Pedro de Castro Picelli em dezembro de 2016. 
O time do Tamoio era composto apenas por homens negros, que, realizando suas partidas em terreno situado bem em frente à sede do clube, mantinha uma tradição existente na cidade desde, pelo menos, a década de 30 e que apontamos aqui:

A compartimentalização racial também foi encontrada no futebol em Rio Claro. Em 1936 teve início na cidade o Festival Esportivo 9 de Julho - Brancos versus Pretos. O evento foi realizado por vários anos, sempre nos feriados de 9 de julho. Tendo como principal atrativo a calorosa partida futebolística entre os times branco, de um lado, e preto, de outro, o festival era organizado para a arrecadação de fundos em prol do Asilo São Vicente de Paula de Rio Claro - por meio do que os "homens de cor" respondiam, certamente não pela primeira vez, ao apelo que lhes fora dirigido por meio da imprensa local em 1932 (PEREIRA, 2008, p. 86).

Com o passar do tempo, as atividades do Tamoio F.C foram se diversificando, inclusive a própria sociedade tem seu nome alterado na década de 1960 para Associação Beneficente Cultural e Recreativa Tamoio. Bailes e coquetéis passaram a ser realizados de maneira muito semelhante aos já apresentados. Em trajes finos, seus membros se socializavam ao som de jazz ao longo de todo o ano e nos períodos carnavalescos, ocupavam o salão para as matinês e ensaios do cordão carnavalesco.

Oriundas de um mesmo período histórico, a relação entre S. B. R José do Patrocínio - e sua "forma anterior" - e Tamoio F.C - depois A.B.C.R Tamoio - deixava mais visível as diferenças sociais entre seus membros quando comparada às relações construídas pelas sociedades anteriores, sendo estas diferenças sempre pautadas nas entrevistas realizadas. Como apresentado até aqui, as sociedades negras foram surgindo desde a década de 30 . Nesse processo, os novos clubes que emergiram eram oriundos de dissidências dos anteriores e constituíram seu corpo diretivo e de sócios a partir da reorganização dos membros dos clubes já existentes. Contudo, a década de 40 traz uma ruptura neste processo, pois neste momento as atividades associativas negras são enfraquecidas consideravelmente, restando passar por um "novo recomeço" com novos objetivos dentro de um cenário social diferente do da década de 1930. Com isso, em nossa hipótese, a distinção entre essas sociedades (S.B.R. José do Patrocínio e Tamoio F.C) e seus membros são mais notáveis, pois fazem parte de uma nova dinâmica social destas sociedades. Um dos elementos desta dinâmica dava centralidade na conquista da sede própria como um de seus escopos centrais dentro de estratégias amplas de combate e resposta ao racismo. A década de 30, como já apresentada por Petrônio Domingues (2010), construía o enfrentamento às práticas discriminatórias "pela via educacional e moral, nos marcos do capitalismo ou da sociedade burguesa". 
A década de 40 traz novos elementos e há o confronto com práticas racistas "pela via educacional e cultural, eliminando o complexo de inferioridade do negro e reeducando racialmente o branco, nos marcos do capitalismo ou sociedade burguesa". Portanto, aquela década busca construir a moral dos sujeitos negros dentro de um sistema social mais amplo ao qual ele deveria tensionar e angariar seu espaço dentro da ideia de inserção. Esta, aposta mais incisivamente na elevação do status social do negro e no questionamento do lugar social branco dentro do confrontamento direto. Isso implica o próprio modo como as sociedades se organizam e trazem novos elementos para esta organização. Portanto, as marcas distintivas a partir dos vínculos empregatícios dos membros dos clubes só podem ser compreendidas, não como uma cisão dentro das práticas associativas onde há uma hierarquização rígida dos membros de uma elite negra e de camadas mais baixas deste grupo, mas dentro de um cenário de reorganização de discursos e práticas destas organizações.

\section{Considerações finais}

Este artigo buscou trazer brevemente um panorama sobre a formação das atividades associativistas negras na cidade de Rio Claro. Obviamente que o assunto não se esgota nestas considerações, contudo procurou-se colocar a conhecimento do leitor sujeitos, ideias e práticas que modularam a vivência republicana de sujeitos negros em uma sociedade extremamente racista.

Agradecimentos: Este texto é parte de pesquisa de mestrado em andamento no Programa de Pós-Graduação de Sociologia da Unicamp iniciada em março de 2018. Financiada em seus dez primeiros meses pela CAPES e no período que se segue a janeiro de 2019 pela FAPESP, devo meus agradecimentos à estas duas instituições, sem as quais seriam inviáveis a dedicação integral a este projeto. É necessário registrar que a pesquisa da qual este artigo é oriundo também compõe o projeto temático financiado pela FAPESP “As cores da cidadania: os clubes negros do estado de São Paulo (1897-1952).

\section{REFERÊNCIAS}

ALBUQUERQUE, Wlamyra. A vala comum da raça emancipada: abolição e racialização no Brasil, breve comentário. História Social, v. 19, p. 91-108, 2010. 
ALBUQUERQUE, Wlamyra. O Jogo da dissimulação. Abolição e cidadania negra no Brasil. São Paulo: Companhia das Letras, 2009.

BILAC, Bianchini. As elites políticas de Rio Claro. Piracicaba; Campinas: UNIMEP; UNICAMP, 2001.

BOSI, Ecléa. Memória e sociedade: lembranças dos velhos. 3 ed. São Paulo: Companhia das Letras, 1994.

CASTRO, Bernadete A. Patrimônio Cultural e Territorialidade Negra em Rio Claro-SP. Espaço \& Geografia, v. 16, n. 2, p. 566-570, 2013.

DEAN, Warren. Rio Claro: um sistema brasileiro de grande lavoura (1820-1920). Rio de Janeiro: Paz e terra, 1977.

DINIZ, Diana. Rio Claro e o café: desenvolvimento, apogeu e crise (1850-1900). [Tese] Faculdade de Filosofia, Ciências e Letras de Rio Claro, Universidade Estadual Paulista "Júlio de Mesquita Filho", 1973.

DOMINGUES, Petrônio. Movimento Negro Brasileiro: alguns apontamentos históricos. Tempo, v. 12, n. 23, p. 100-122, 2007.

ESCOBAR, Giane Vargas. Clubes sociais negros: lugares de memória, resistência negra, patrimônio e potencial. [Dissertação] Santa Maria: UFSM, 2010.

PEREIRA, Flavia A. de Souza. Organizações e espaços da raça no oeste paulista: movimento negro e poder locar em Rio Claro. Tese de Doutorado pela Universidade Federal de São Carlos; 2008

\section{Como referenciar este artigo}

PICELLI, Pedro de Castro. O associativismo negro em Rio Claro: sujeitos, práticas e ideias na República. Rev. Sem Aspas, Araraquara, v. 8, n. 1, p. 57-73, jan./jun. 2019. ISSN: 2358-4238. DOI: $10.29373 /$ sas.v8i1.12585.

Submetido em: 29/05/2019

Aprovado em: 30/06/2019 